\title{
Analysis and Perspective on Significance of Modern Logistics to Fujian's Foreign Trade Development
}

\author{
Manli Weng \\ Research Center for Fiscal and Financial development in Haixi \\ (Minjiang University), Fuzhou 350121, China \\ 550974783@qq.com
}

Keywords: Modern logistics; Foreign trade; Economic growth

\begin{abstract}
With the rapid development of economic globalization and in-depth, Chinese import and export trade is growing rapidly, while having driven the rapid development of modern logistics. As "the third profit source", the economic growth of modern logistics industry with the advantages of efficiency and integration decreases the cost of international trade and promotes the development of foreign trade. As a coastal city of Fujian, the logistics industry and the level of foreign trade have increased obviously. However, the bottleneck of its logistics industry is unfavorable to our province's foreign trade. Based on the analysis of the weak growth of foreign trade due to the insufficient development of modern logistics, this paper explores the coordinated development strategies of modern logistics and foreign trade in Fujian Province. As a result, it can create a new growth point for the development of international trade.
\end{abstract}

\section{Current Development Status of Modern Logistics in Fujian}

Ports have Geographical Advantages but are less Developed than other Coastal Cities. Fujian is a province on the southeast coast of mainland China, with Taiwan to the east, across the Taiwan strait. The coastline is the longest in China and has 125 large and small bays. Thanks to its unique advantages of geographic location, Fujian is blessed with several major ports, with Xiamen port and Fuzhou port ranking the largest in the province. A regional layout of the ports is gradually formulated in a way that Fuzhou and Xiamen ports serve as the two major ports and Quanzhou port, Meizhou Bay port and many other ports as the supporting ports (see Fig.1). In recent years, by speeding up its economic trade with Taiwan, seizing developing opportunities and enhancing external cooperation, Fujian embraced a golden age for port development and yielded many fruitful results: During 2005 to 2013, total investment of 68.2 billion yuan was accomplished; seaport container throughput in 2016 achieved 14.402 million TEU, total weight reached 186.55 million tons, and created 1.08 billion yuan GDP, showing an increase of 370,000 TEUs and 9 million types of goods as compared with the year of 2015. Despite these achievements, the overall competitiveness and strength are still at the stage of low level compared with other ports of coastal provinces. Cargo throughput of Xiamen and Fuzhou ports in first half of 2017 ranked respectively the 19th and 24th place nationally, which is far from Zhoushan port (ranked 1st nationally), Shanghai port (ranked 2nd nationally) and Suzhou Port (ranked 3rd nationally) and fails to efficiently serve for Fujian's Ocean Strategic Objectives. 


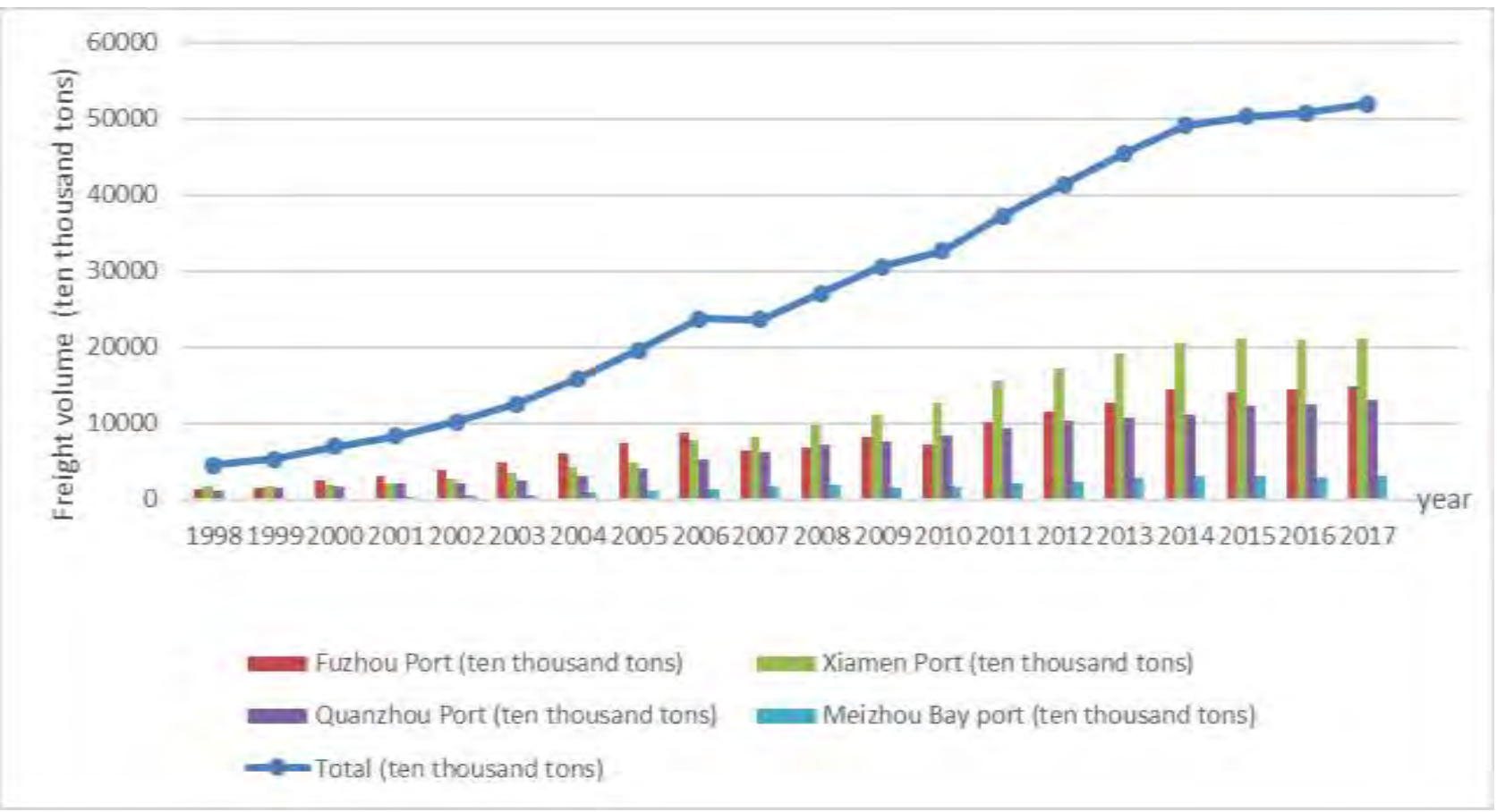

Figure 1. 1997-2016 Fujian major port cargo volume and total cargo volume

Imbalanced Development are Found in Railway and Highway Construction. Due to Fujian's mountainous terrain, it is more difficult to develop highways and railways in Fujian. Since 21st century, Fujian has experienced fast development in building highways and railways under the State's strong policy support, which however, were mainly located in eastern Fujian province. In 2017, 1.8-billion-yuan investment was achieved. Daily traffic of arterial highway grew 1\% from the previous year, among which the traffic capacity of National Expressway Net increased by $4.2 \%$. From regional perspective, traffic capacity of coastal area was 2.7 times as that of mountainous region. In general, highways and railways in Fujian province are well-developed, yet imbalance still exists between the east and west, with western region characterized by backward transportation condition and incomplete infrastructure.

Air Transport Maintains Good Growth Momentum and Shows an Increasing Tendency Year by Year. Fujian was one of the last provinces to open air transport after the founding of the People's Republic of China. In 1974, civil aviation was restored. The opening policy had played a great role in promoting civil aviation development in Fujian province. Currently, there are six military and civilian airports in Fujian, recording a cargo turnover capacity of 233,900 tons, an increase of about 5.9\% year on year. The completion of Sanming Airport in 2016 has also contributed to the province's increase in air transport volume. In recent years, Fujian province has gradually opened multiple air routes to facilitate the development of logistics and has established a closer communication with other countries of the world. Goods from different regions no longer needs to pass through large international airports such as Beijing and Shanghai. The development in Information technology has promoted air transportation and becomes the pivot point for the maturity and improvement of modern logistics industry. Fujian is a province with well-developed networks. Information transmission is fast and convenient in the region and information platform construction is gradually perfecting. Through information construction, manpower, material resources and investment costs can be largely reduced during transportation. Compared with the traditional logistics industry, civil aviation transport is considered one of the representatives of modern logistics and Fujian air logistics is now becoming a driving force of modern logistics with its growth trend year after year. 


\section{Present Status of Foreign Trade Development in Fujian}

With economic globalization and the deepening of international labor division, foreign trade has become a driving force for economic growth. As a coastal province in southeast China, Fujian has a geographical advantage to develop its foreign trade and had showed a rapid growth in foreign trade sector. In recent years, however, imports and exports went steady and even began to leap downward.

In 2008, the financial crisis dealt a severe blow to Fujian economy, especially to the foreign trade sector. Total imports and exports decreased to $\$ 796.49$ billion, a drop of 6 percent year on year. In 2010, foreign trade in Fujian experienced a sharp resurgence from the depths of the financial crisis and grew even faster. Total imports and exports reached $\$ 1,087.8$ billion, up 36.6\% year on year. After two years' rapid growth, it came steady again. Foreign trade began to decline in 2014 and in 2016, it dropped back to the same level of year 2012 (see Fig.2).

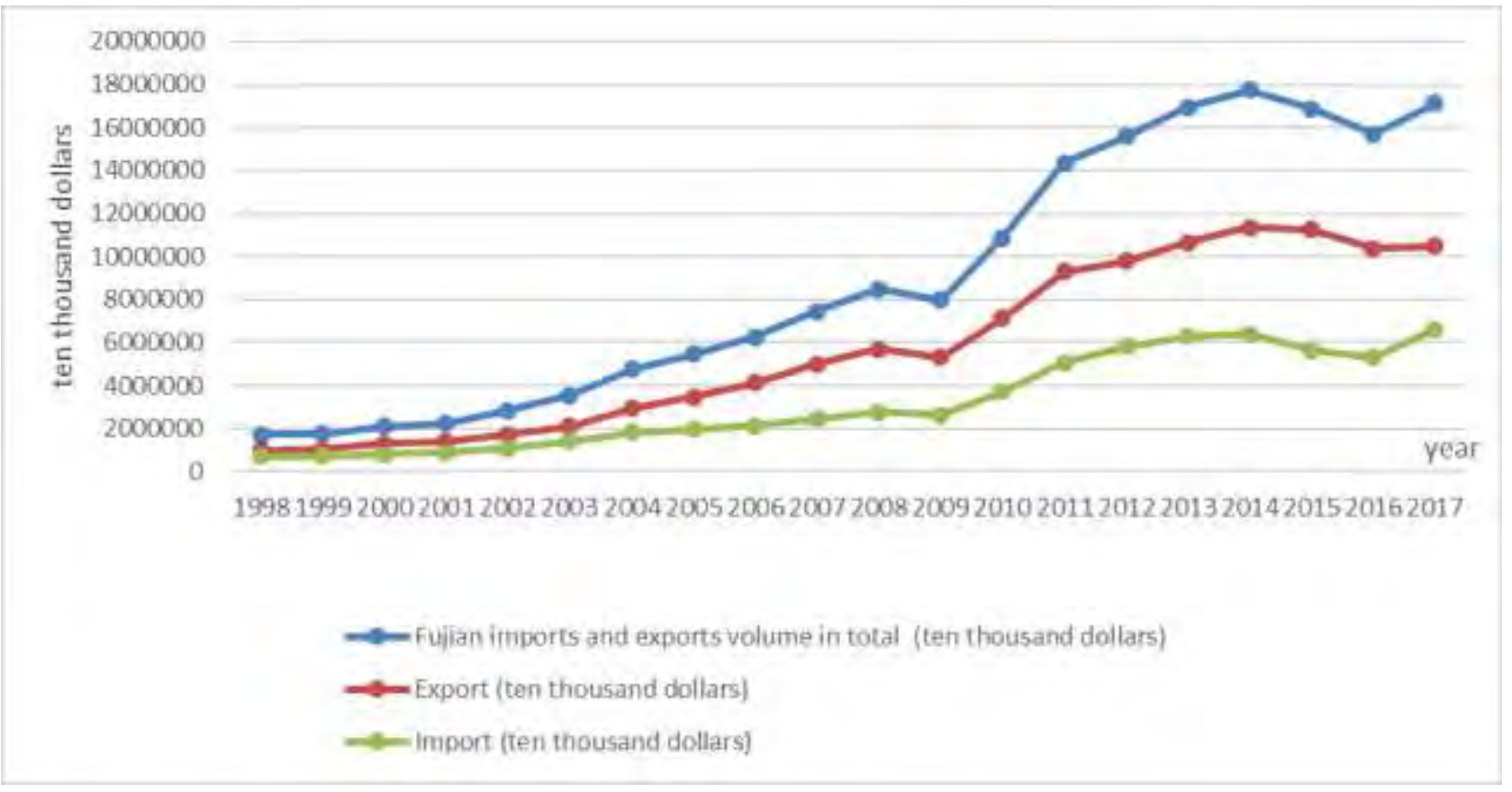

Figure 2. Fujian Imports and Exports Trend in 1997-2016

In recent years, with the development of multi-outlet international market, bilateral trade between Fujian and many other countries and regions has been developing well and bilateral trade volume continues to increase. Both imports and exports showed a growth trend. According to statistics of 2016 (Table 1), Fujian's export to Asia achieved \$49 million in maximum. Next to it were North America and Europe and Latin America, with Africa and Oceania being the least. Traditional export market still takes the large proportion of the total exports volume; Exports to Latin America and Africa marked the highest growth rate in 2016, which is 12.7 times the figure of year 2000. Although exports to Asia, Europe and North America showed a lower growth rate, the overall exports to each continent displayed a fluctuating upward trend; On import sector, the largest imports are still from Asia and the least is from Oceania, with the rest of the continents getting closer year by year. Fujian has maintained a favorable balance in foreign trade in recent years, displaying a good development momentum. 
Table 1 Major-year Imports and Exports of Fujian to Each Continent

\begin{tabular}{|l|l|l|l|l|l|l|}
\hline & $\begin{array}{c}\text { Country(region) } \\
\text { Unit: ten thousand US dollars }\end{array}$ & 2000 & 2005 & 2010 & 2015 & 2016 \\
\hline \multirow{5}{*}{ Imports } & Asia & $\mathbf{6 2 5 , 3 4 5}$ & $\mathbf{1 , 3 9 7 , 8 0 6}$ & $\mathbf{2 , 4 6 6 , 7 1 3}$ & $\mathbf{3 , 0 3 9 , 0 6 7}$ & $\mathbf{2 , 8 2 5 , 6 1 1}$ \\
\cline { 2 - 7 } & Europe & $\mathbf{8 8 , 7 3 4}$ & $\mathbf{2 0 5 , 5 0 6}$ & $\mathbf{4 3 6 , 4 0 1}$ & $\mathbf{7 6 8 , 1 6 6}$ & $\mathbf{6 6 3 , 6 1 9}$ \\
\cline { 2 - 7 } & North America & $\mathbf{8 6 , 0 3 0}$ & $\mathbf{2 0 9 , 5 0 6}$ & $\mathbf{4 2 0 , 2 3 4}$ & $\mathbf{9 0 6 , 7 4 8}$ & $\mathbf{6 6 3 , 8 4 6}$ \\
\cline { 2 - 7 } & Oceania & $\mathbf{1 2 , 3 4 2}$ & $\mathbf{2 7 , 8 4 1}$ & $\mathbf{1 0 8 , 2 0 6}$ & $\mathbf{3 0 1 , 4 5 5}$ & $\mathbf{4 2 8 , 1 8 7}$ \\
\cline { 2 - 7 } & Latin America and Africa & $\mathbf{1 9 , 0 5 3}$ & $\mathbf{1 1 6 , 2 7 6}$ & $\mathbf{2 9 6 , 9 5 1}$ & $\mathbf{6 0 0 , 8 7 6}$ & $\mathbf{7 3 3 , 4 2 6}$ \\
\hline \multirow{5}{*}{ Exports } & Asia & $\mathbf{5 9 8 , 8 3 8}$ & $\mathbf{1 , 4 5 1 , 2 1 3}$ & $\mathbf{2 , 9 0 2 , 3 2 3}$ & $\mathbf{5 , 2 6 6 , 7 0 7}$ & $\mathbf{4 , 9 3 4 , 2 3 0}$ \\
\cline { 2 - 7 } & Europe & $\mathbf{2 4 3 , 5 9 7}$ & $\mathbf{7 8 2 , 4 5 6}$ & $\mathbf{1 , 6 4 0 , 5 4 7}$ & $\mathbf{2 , 1 0 4 , 3 0 1}$ & $\mathbf{2 , 0 1 0 , 7 5 8}$ \\
\cline { 2 - 7 } & North America & $\mathbf{3 4 2 , 5 2 6}$ & $\mathbf{9 3 4 , 3 8 9}$ & $\mathbf{1 , 6 0 5 , 5 0 9}$ & $\mathbf{2 , 3 3 8 , 1 0 0}$ & $\mathbf{2 , 1 3 7 , 6 6 6}$ \\
\cline { 2 - 7 } & Oceania & $\mathbf{2 2 , 2 2 9}$ & $\mathbf{5 8 , 1 0 4}$ & $\mathbf{1 3 3 , 9 5 0}$ & $\mathbf{2 1 5 , 5 1 4}$ & $\mathbf{2 1 7 , 7 7 8}$ \\
\cline { 2 - 7 } & Latin America and Africa & $\mathbf{8 3 , 6 3 8}$ & $\mathbf{2 5 8 , 0 3 2}$ & $\mathbf{8 6 4 , 5 4 6}$ & $\mathbf{1 , 3 4 3 , 3 9 0}$ & $\mathbf{1 , 0 6 6 , 8 1 8}$ \\
\hline
\end{tabular}

\section{Foreign Trade Problems Caused by Insufficient Development of Modern Logistics}

Low Logistics Information Level Hampers Foreign Trade Development. Logistics information construction is the foundation for building the intelligent and automatic logistics. Undistorted and complete information guarantees the maximum utility of supply chain management. Logistics information construction in Fujian is now in a state of low-level and grows in slow rate, which restricts the improvement of supply chain management, thus hampering foreign trade development in Fujian. First, most logistics companies in Fujian province are at the primary stage of information construction, only being able to meet companies' ordinary business operation. Second, logistics enterprises are tended to be slow in response to new-techs and show a poor adaptive ability in applying the new-techs, resulting in a slow speed of information construction. One case is that, countries of well-developed logistics have already widely applied the intelligent and automatic technologies to handle logistics operations such as storage, transportation, loading and unloading, while such technology is poorly applied in companies of Fujian or even nationwide and the technologies of these companies are still remained in preliminary level.[1] Third, logistics information platform construction is lagging behind. Lastly, logistics information standardization advances slowly, unable to fit the information development of modern logistics.

Inadequate Logistics Policies Restrict the Fast Development of Foreign Trade. The existing laws and policies on logistics have played a certain role in promoting the healthy development of logistics industry, but they are still unable to meet the fast development of logistics industry. Policies are often in a very timely and targeted manner and poses a direct influence on logistics activities. In Fujian, the geographic advantages and early opening-up policy both have contributed a lot to the province's logistics development. However, the existing laws and policies fail to fully reflect and implement the principles of present market economy in innovation process of free trade zone construction, bonded warehouse development and cold chain logistics, and are lack of international perspective. Policies shall be made, updated and implemented through government's close interaction with logistics companies to ensure that these policies are prompt and appropriate for the province's foreign trade development.

Incomplete Logistics Infrastructure Becomes an Obstacle for Foreign Trade Development. Foreign trade contracts are carried out by international logistics. It requires modern logistics to guarantee an efficient logistics operation and even higher standard of operations are required in transporting fragile foreign goods of large value. Among all export costs, transportation takes the bigger proportion, the cost of which needs to be well-controlled and reduced, so as to improve the 
competitive strength of exported goods. [2] However, cargo transport growth in Fujian province in these years were below the value-added of GDP and Secondary Industry. One major reason is the incomplete logistics infrastructure, which is intensively reflected in the following issues: inadequate transportation capacity of coastal ports, incomplete port construction, less attraction to nearby logistics, and a singularized mode that can not meet the diversified service requirement. Another reason is the insufficient connection between ports and railway transportation. Railway and highway development in Fujian is in an imbalanced state due to the geographic difference between eastern coastal area and western mountainous region, characterized by intensity development in the east and sparsity condition in the west. As highway and railway transportation are all essential to port logistics and air logistics, the saturated railway transportation may lead to poor efficiency of cargo transport and fail to handle the increasing logistics volume brought by fast trade development. Poor highway performance also may cause cargo jams and result in cost increase. Therefore, it is vital to conduct the highway and railway construction.

\section{Measures and Suggestions on Achieving a Coordinated Development of Fujian Modern Logistics and Foreign Trade}

\section{Modern Logistics Hardware Facilities shall be Enhanced}

Works shall be Done to Complete the Transportation Network. Due to the singularized information mode of Fujian logistics, many companies tend to choose the same transportation tool even this means a higher cost. This type of transportation has resulted in the waste of resources and the increase in cost during the process transportation. Therefore, multimodal transportation shall be enhanced to reduce such cost. Firstly, there shall be an upgradation in basic transportation infrastructure to ensure a smooth operation of railway and highway transportation and avoid any saturation conditions. In water transportation, works shall be done to improve waterway traffic capacity and ensure an orderly pass and regulated harbor of ships ,so as to cut the time for waiting. And for air transportation, transport lines between air ports, ports and each logistics parks shall be constructed and enhanced, and works shall be done to enhance the construction of junctions between railways, highways and airports, so as to take the advantage of speed strength of air transportation to meet the multi-layered and multi-region cargo transportation and export.

Rationally Building Logistics Parks and Creating New Port Model. A comprehensive service construction shall be conducted on the basis of the existing logistics parks, and at the same time building new parks and bonded areas. This is the sure way to be taken to improve port transportation capacity in modern logistics industry. Therefore, the construction of bonded areas in the province shall be enhanced and supervised by the government to ensure a constant display of their strength. The management and construction body of ports and docks shall be separated. In this way, companies are able to demonstrate their strengths and high efficiency through the application of advanced management model and reduce the risk of capitals raised for port construction. It is also conducive for ports to deliver better services for logistics enterprises and foreign trade companies and ultimately promotes foreign trade development.

Logistics Information Construction shall be Strengthened. The current low information level in logistics industry has posed a barrier for foreign trade development. The logistics information construction is aimed to realize a real-time information exchanging between logistics companies and their clients. Only by constantly improving EDI (Electronic Data Interchange) can the development of modern logistics and the province's logistics operation and efficiency be achieved. Information construction in Fujian shall be centered on such operations as full utilization of bar codes, GPS positioning, application of EDI and other technologies, so as to satisfy business operations of cargo tracking, electronic declaration and receipt and expenditure settlement etc. For example, RFID warehouse management system can be introduced to logistics companies to enhance their warehouse utility rate, which may largely reduce their logistics costs. Government shall be the main capital source to encourage the construction of information network, push more entities to participate in the integrated information platform, promote information resource sharing, and guide logistics companies to learn experiences from leading companies of the province. Information 
improvement is the key to reduce logistics costs, which will ultimately promote the development of foreign trade.

Seeking New Opportunities from the "Belt and Road" Initiative. Silk Road Economic Belt and 21st Century Maritime Silk Road are China's major strategic decisions in response to the changing global political and economic situations. Progress in policy communication, infrastructure linkage, trade flow, financing arrangements and friendly exchanges between the people are the major focus of The "Belt and Road" Initiative, among which infrastructure linkage and trade flow are two main focus in construction field.[3] In air transportation area of modern logistics, we can enlarge trade areas and promote economic growth by seeking cooperation with counties along the Belt and Road on commodities suitable for high price but efficient air transportation (such as electronic products and biological medicine produced in Fujian). Economic development zones are another advantages Fujian can take to drive its air trade development. Government shall at the same time issue responding policies to release restrictions on air transportation market access and encourage win-win cooperation of multi-way partnership. In port logistics area, connections between railway, highway and each port shall be strengthened. Capitals shall be invested to complete ports' collection and distribution facilities, so as to achieve the modernization of each port. Measures shall be taken to strengthen the planning and construction of areas along ports, railways and highways and vigorously develop efficient and convenient multimodal transportation. Under the "Belt and Road" Initiative, commodities of all kinds are able to be distributed in large volume and fast speed home and abroad, providing great development opportunities for export-oriented industrial enterprises. At the same time, it also poses a challenge to logistics industry in Fujian. Bonded logistics, as an integrated logistic model combining functions such as commodity inspection, taxation and foreign exchange settlement, is an effective solution for export-oriented industrial enterprises to handle export operations such as export rebates and customs clearance. [4]

\section{Acknowledgements}

Funded by Research Center for Fiscal and Financial development in Haixi (Minjiang University) (No. HXCJ1708)

\section{References}

[1] S.Z. Gu, L. Fang and R. Li, Countermeasures for Upgrading Logistics Industry in China, Economic Review.03(2014)1-7.

[2] H. Tao, Research on the Combination of Modern Logistics and Foreign Trade to Promote Local Import and Export Trade, Marketing Research. 11(2013)57-59.

[3] X.F. Fan, S.Yu, Empirical Analysis on Impact of Logistics Performance of Maritime Silk-Road Economic Belt on China's Import and Export Trade, Journal of Xi'an Jiaotong University (Social Sciences).03(2015)13-20.

[4] C.L. Wang, International Logistics Management, first ed., Hefei University of Technology Press Co., Ltd., Hefei, 2014.

[5] J. Zhong, Optimization of International Trade Logistics Industry in China-ASEAN Free Trade Zone, Logistics Technology.13(2014)57-59.

[6] Q. Liu, Q.J. Liu and M. Liu, Empirical Research on Trade Potential between Xinjiang and the Eurasian Economic Union under the "Silk Road Economic Belt", Economic Geography.04(2018)65-72. 